\title{
Risk of mortality associated with formoterol: a systematic review and meta-analysis
}

\author{
M. Wijesinghe*, M. Weatherall" ${ }^{\#}$ K. Perrin*, M. Harwood* and R. Beasley*,
}

\author{
ABSTRACT: There is concern long-acting $\beta$-agonist (LABA) drugs may increase the risk of asthma \\ mortality.
}

We undertook a systematic review which included the AstraZeneca Formoterol Clinical Trial Safety Database and Novartis Food and Drug Aministration Formoterol Briefing Document. Randomised controlled clinical trials of duration $\geqslant 4$ weeks that compared formoterol with a nonLABA comparator treatment in asthma were included in a meta-analysis of the risk of all-cause mortality and asthma death. Simple contingency tables, Peto's one-step method and a Bayesian analysis were used.

There were 42 deaths (nine from asthma) recorded in 62 studies with 49,327 subjects. The simple contingency table odds ratio for risk of all-cause mortality with formoterol was $1.1(95 \% \mathrm{Cl}$ 0.6-2.2) and for asthma death was 2.7 (95\% Cl 0.5-26.7). Analyses by the other methods using both "as randomised" and "as exposed" classifications of treatment gave similar risk estimates with wide confidence and credible intervals.

We conclude that there was insufficient power to determine whether formoterol increases the risk of mortality. However, the point estimates of a 2.0- to 3.2-fold increased risk of asthma death are not reassuring and add weight to evidence that LABA use in certain circumstances may increase the risk of asthma mortality.

KEYWORDS: Asthma, formoterol, meta-analysis, mortality, systematic review

$\mathbf{T}$ he history of the development of inhaled sympathomimetic drugs in the treatment of asthma has been characterised by safety concerns, in particular over whether their use might increase the risk of mortality [1-6]. The concerns regarding the safety of the long-acting $\beta$ agonist (LABA) drugs salmeterol and formoterol represent the latest chapter in this history [7-11]. The main evidence that LABAs may increase the risk of mortality comes from two large randomised controlled trials, the UK-based Salmeterol Nationwide Surveillance Study (SNSS) [9], and the USAbased Salmeterol Multicentre Asthma Research Trial (SMART) [10]. These studies reported that the use of salmeterol resulted in a statistically nonsignificant three-fold and a statistically significant four-fold increase in asthma death, compared with regular salbutamol and placebo, respectively. However, in the SMART study there was no increase in mortality observed with salmeterol in subjects taking concomitant inhaled corticosteroid (ICS) therapy. Although this subgroup analysis was limited by low power, it did suggest that the risk may be restricted to the use of salmeterol as monotherapy in patients with unstable asthma not under regular medical care. This finding was consistent with case-control studies that reported that the use of LABAs does not increase the risk of a life-threatening attack or sudden death from asthma [12-16]. While some of these epidemiological studies were also limited by low power and wide confidence intervals, this was not the case with the large UK-based case-control study [12], in which there was no evidence of any positive association between LABAs and asthma death.

In response to this conflicting evidence, the Food and Drug Administration (FDA) has confirmed the availability of both salmeterol and formoterol, but has required "black box" warnings on their product labels [17]. The FDA also recommended that further research was required to improve the understanding of the nature and magnitude of risk of LABA therapy. Owing to the rarity of death in asthma clinical trials, one approach to address this recommendation is to undertake meta-analyses of all clinical trials of the specific LABAs salmeterol and formoterol. This approach
AFFILIATIONS

${ }^{*}$ Medical Research Institute of New Zealand, Wellington,

\#University of Otago Wellington,

Wellington, New Zealand.

"University of Southampton,

Southampton, UK.

CORRESPONDENCE

R. Beasley

Medical Research Institute of New

Zealand

PO Box 10055

Wellington 6143

New Zealand

E-mail: Richard.Beasley@

mrinz.ac.nz

Received:

Oct 222008

Accepted after revision:

March 102009 
has been undertaken in a recent meta-analysis of the risk of severe adverse events in patients receiving salmeterol plus ICS compared with ICS alone [18]. It reported a reduction in risk of severe exacerbations and no effect on risk of asthma-related hospitalisation. However, owing to the very low rate of asthma-related death (one death amongst 20,966 participants), it was not possible to determine whether salmeterol added to ICS therapy, as recommended in international guidelines [19, 20], influenced the risk of death.

Recently, a meta-analysis of the risk of asthma mortality associated with formoterol treatment has been reported [21]. The key findings were that, owing to the very low asthma death rate, the analysis had insufficient power and, although the point estimates were consistent with an increased risk of death in patients taking formoterol, the confidence intervals were wide and the differences not statistically significant. The design of the study could be considered flawed, in the respect that clinical trials in which there was no non-formoterol comparator arm were included. It was outlined in an accompanying editorial that this reduced the estimates of risk of asthma mortality associated with formoterol treatment [22]. Other methodological issues were that studies of formoterol conducted by Novartis were not included, and that multiple subgroup analyses were carried out, which were not justified due to the small number of deaths included in the database. In the present manuscript, we report a systematic review and meta-analysis of randomised controlled trials of formoterol that overcame these methodological issues, in order to determine whether its use is associated with an increased risk of mortality. Several different analytical methods have been used to investigate the sensitivity of the estimates of risk of asthma mortality.

\section{METHODS}

\section{Search strategy}

A search of studies containing the key words "asthma" and "formoterol" or "eformoterol" was conducted from Medline, the Cochrane Database of Systematic reviews, the Cochrane Central Register of Controlled Trials, EMBASE and CINAHL to March 2007. The reference lists of all relevant studies were also examined. Trials were not excluded on the basis of language. Abstracts and poster presentations were also included. We also requested safety data from AstraZeneca (London, UK) and Novartis (Basel, Switzerland). AstraZeneca provided us with a safety database of all clinical trials of formoterol. Novartis was unable to provide us with a similar database, but referred us to the Novartis submission to the FDA Pulmonary Allergy Drugs Advisory Committee meeting [23].

\section{Inclusion criteria}

For inclusion in the meta-analysis, studies had to be randomised, controlled, clinical trials of duration $\geqslant 4$ weeks that compared formoterol (as a separate or combination ICS/ LABA inhaler) with a non-LABA comparator treatment in the management of asthma.

\section{Exclusion criteria}

Non-randomised trials, cross-over studies and studies of duration $<4$ weeks were excluded. Studies with no comparator treatment and those using salmeterol as the sole comparator were also excluded. Trials in which salmeterol represented one of a number of different comparator treatments were included, but only the non-salmeterol comparator treatments were included in the analysis.

\section{Data extraction}

Two reviewers extracted information on deaths occurring during the randomised treatment period from the published studies. Investigators were contacted if the published manuscript did not state whether or not any deaths occurred. If any discrepancies occurred between the published data and the AstraZeneca database or Novartis FDA submission, the latter were taken as definitive. Deaths were categorised as either asthma-related or due to another cause.

\section{Outcome measures}

The primary outcome variable was total deaths. The secondary outcome variable was deaths due to asthma.

\section{Statistical methods}

Three statistical methods were used to determine the risk of mortality associated with formoterol treatment. The first method was the simple contingency table odds ratio carried out by an exact method in SAS version 9.1 (SAS Insitute Inc., Cary, NC, USA) using the "FREQ" procedure. The second method was Peto's one-step odds ratio, carried out according the formulae given by BRADBURN et al. [24]. For the third, the Bayesian method was implemented in WinBUGS 1.4 using the package "R2WinBUGS" in the $\mathrm{R}$ statistical program [25]. A Poisson distribution with an offset related to the number of weeks of observation and number of subjects in the trial was modelled for the formoterol and comparator arms. Two prior distributions were used: "vague priors" on the distribution of the effect size, and "informative priors" based on the SMART trial confidence limits for the outcome variables [10]. The prior used for total deaths was the confidence interval for the odds ratio for all deaths of 0.8-2.1 from the SMART trial [10]. For asthma death, the confidence interval of 1.2-15.3 was used.

The primary analyses were undertaken according to the formoterol or comparator treatments at randomisation. Sensitivity analyses were also undertaken according to exposure to formoterol (i.e. defining as exposed to formoterol those subjects randomised to comparator treatment who received formoterol as routine maintenance therapy) and with the exclusion of subjects receiving salmeterol as routine maintenance therapy (i.e. patients randomised to formoterol or comparator treatment who received salmeterol as routine maintenance therapy were excluded). This approach was required because, in the RELIEF (Real Life Effectiveness of Oxis ${ }_{\circledR}$ Turbuhaler ${ }^{\circledR}$ as-needed in asthmatic patients) study [26], which included over half of all deaths included in the metaanalysis, about $30 \%$ of subjects had continued use of regular maintenance formoterol or salmeterol treatment throughout the study.

\section{RESULTS \\ Study characteristics}

The flow of studies found by the search strategy, as recommended by the QUOROM (Quality of Reporting of Metaanalyses) statement, is shown in figure 1.62 studies with a total of 49,327 subjects met the inclusion criteria for the analysis (see reference list of studies in online data supplement). A total of 
27,821 subjects were randomised to formoterol-containing products and 21,506 to non-LABA products (see table E1 in the online data supplement). This represented 12,074 person-yrs of formoterol treatment and 10,408 person-yrs of comparator treatment. The comparator treatment was placebo (or no treatment), short-acting $\beta$-agonist and other therapies in 47,25 and four studies, respectively, with 14 studies having more than one comparator treatment. The mean (range) duration of the trials was 18 (4-52) weeks. The age range of participants was 4 $91 \mathrm{yrs}$, and 11 studies were carried out in children alone.

The AstraZeneca Formoterol Clinical Trials Safety Database provided detailed information on 33 studies which met the criteria for inclusion in the analysis. The 33 studies included a total of 37,419 subjects representing $75.9 \%$ of the subjects included in the analysis. The Novartis FDA formoterol submission presented data in summary form from an integrated database of all controlled trials of formoterol including 5,907 subjects exposed to formoterol and 3,684 subjects exposed to comparator products.

\section{Concomitant ICS}

In 31 out of the 62 studies, all patients received an ICS as part of the randomised treatment. In one study, $60 \%$ of patients

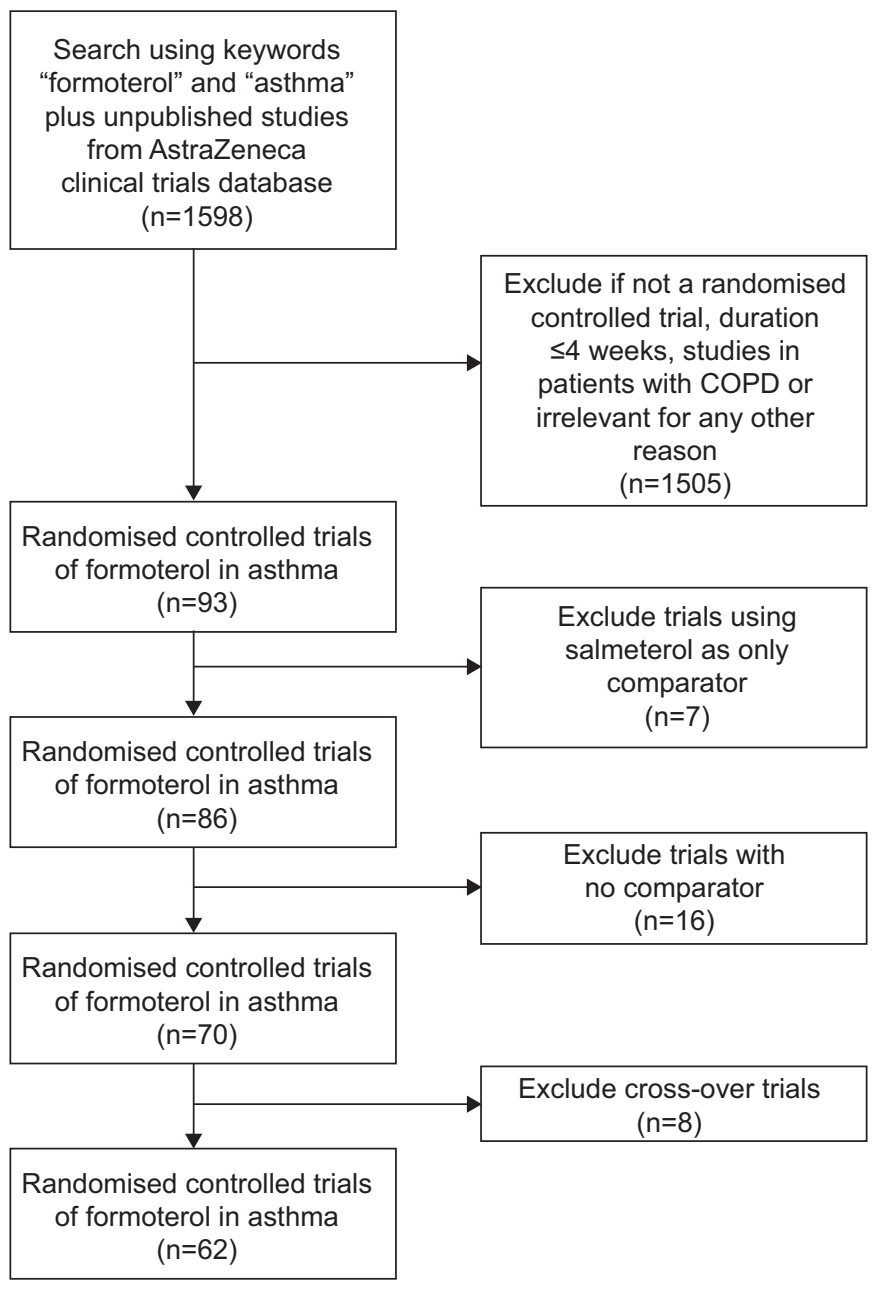

FIGURE 1. Search strategy. COPD: chronic obstructive pulmonary disease. received an ICS as part of their randomised treatment [27]. In eight studies, ICS were disallowed as part of the trial protocol. In the remaining 22 studies, concomitant ICS were allowed and were reported to be used by $44-100 \%$ of subjects.

\section{Documentation of deaths}

Of the 62 studies, clinical details of deaths were available from the 33 studies included in the AstraZeneca database. An additional seven studies reported whether any deaths had occurred in the published manuscript. We attempted to contact the principal or senior authors from the remaining 22 studies to gain information on deaths, and received responses for 13 of these studies. There were six deaths identified in the AstraZeneca database which were not reported in the published manuscripts [28-31]. The cause of death in the study of PLESKOW et al. [32] was stated to be cardio-respiratory; however, in the Novartis FDA submission, this was revised to "asthma-related death". In the report by VON BERG et al. [33], the death was initially attributed to a subarachnoid haemorrhage; however, the AstraZeneca database reported the cause of death as respiratory failure/asthma related, as subsequently reported in an erratum [34].

There were differences in the details of the deaths in the RELIEF study [26], between those reported in the published manuscript and in the AstraZeneca database. These need to be presented in detail as over half the deaths included in the present meta-analysis occurred in the RELIEF study. The AstraZeneca database reports that 17,862 patients were randomised to receive 6 months as-needed treatment with formoterol $4.5 \mu \mathrm{g}$ or salbutamol $200 \mu \mathrm{g}$, whereas the published manuscript reported that 18,124 patients were randomised. The AstraZeneca database reported that by randomisation there were 15 deaths in the formoterol group and nine deaths in the salbutamol group. In contrast, the published manuscript stated that there were 13 deaths in the formoterol group and 11 deaths in the salbutamol group. In response to our query regarding this difference, AstraZeneca advised that this difference was because one patient randomised to salbutamol erroneously received formoterol, while another patient, also randomised to salbutamol, exchanged medication with a formoterol-randomised patient at a physician visit and died 2 days later; the physician could not determine which drug was used during these 2 days. AstraZeneca also advised that regulatory authorities worldwide were informed that there were 15 and nine deaths in the formoterol and salbutamol groups, respectively. In accordance with the intention to treat principle, 13 and 11 deaths in the formoterol and salbutamol treatment groups were used in the primary analysis by randomisation, whereas 15 and 9 deaths respectively were used in the analyses by exposure.

Another important issue relating to the RELIEF study was the continued use of regular maintenance LABA treatment in $\sim 30 \%$ of the subjects throughout the study. There were 2,919 subjects on maintenance salmeterol treatment, of whom 1,429 and 1,490 were randomised to formoterol and salbutamol, respectively. There were 1,901 subjects on maintenance formoterol treatment, of whom 932 and 969 were randomised to formoterol and salbutamol respectively. When subjects receiving maintenance salmeterol were excluded, there were 8,466 subjects who were exposed to formoterol but not exposed 
to salmeterol, and 6,477 subjects exposed to salbutamol, but not exposed to either formoterol or salmeterol (see figure E1 in the online data supplement). No other studies included in the meta-analysis included subjects who were on maintenance concomitant salmeterol or formoterol treatment, which was continued throughout the study.

\section{Main findings}

There were nine deaths due to asthma (table 1), and 33 deaths due to other causes, of which 18 were attributed to cardiac causes (table 2) [26, 28-39]. Among the patients who died from asthma, five out of the seven patients randomised to formoterol were prescribed ICS (either as randomised or background maintenance therapy), and one out of two patients randomised to non-LABA comparator treatment was prescribed ICS (either as randomised or background maintenance therapy).

Simple contingency table odds ratios for risk of mortality associated with formoterol treatment at randomisation are shown in table 3. The 1.1- and 2.7-fold increased risk of all cause mortality and death from asthma with formoterol treatment were not statistically significant, and the estimates of risk had wide confidence intervals (95\% CIs 0.6-2.2 and 0.526.7, respectively).

Similar estimates of risk associated with formoterol treatment at randomisation were observed with the Peto's odds ratios, utilising fixed and random effects models with odds ratios of 1.2 (95\% CI 0.6-2.2) and 2.8 (95\% CI 0.7-10.4) for all cause mortality and asthma death, respectively (table 3 ).

The Bayesian estimates of risk associated with formoterol treatment at randomisation are shown in table 3 . The posterior estimate (credible interval) of a 3.2 (1.3-8.7)-fold increased risk of asthma death was based on the prior four-fold increased risk of asthma death from the SMART study [10].

In the sensitivity analyses, when formoterol treatment was based on exposure (maintenance and randomised treatment), and subjects exposed to salmeterol as concomitant maintenance therapy were excluded, there were 36 deaths in total, of which eight were due to asthma (table 1). Similar estimates of risk were observed for the three methods of analysis when formoterol and comparator treatments were assessed by exposure in this way (table 4).

\section{DISCUSSION}

This systematic review and meta-analysis has identified that there is insufficient power from randomised controlled trials to determine whether formoterol treatment is associated with a significantly increased risk of asthma mortality. However, the point estimates of a 2.0- to 3.2-fold increased risk of asthma death with formoterol treatment are not reassuring and add weight to the evidence that the use of LABAs in certain circumstances may increase the risk of asthma mortality. Further research is urgently required to determine the role of LABA therapy in asthma mortality and this may require casecontrol studies rather than clinical trials, which are inherently difficult in addressing the risk associated with such a rare adverse event as death from asthma.

\section{Methodological issues}

There are a number of methodological issues that need to be considered in order to interpret the study findings. The first is whether all randomised controlled trials were identified for inclusion in the meta-analysis. We are confident that all AstraZeneca-funded studies were included through AstraZeneca providing their clinical trials safety database of all published and unpublished clinic trials of formoterol which has been submitted to regulatory authorities worldwide. Unfortunately we were not provided with the similar Novartis database, but are confident that with the Novartis FDA submission and the extensive search strategy that all published studies funded by Novartis were also identified. Using this approach, a total of 62 studies of almost 50,000 subjects involving around 22,500 patient-yrs of treatment was included in the meta-analysis. This represented a modest increase in power compared with the recent formoterol metaanalysis which included almost 40,000 subjects involving around 20,000 patient-yrs of treatment from studies with a non-formoterol comparator group [21].

This approach led to data being accessed from different sources, including the AstraZeneca safety database, the Novartis FDA submission, published manuscripts and abstracts. Differences existed in the data documented for some

\section{TABLE 1 Asthma-related deaths}

\begin{tabular}{|c|c|c|c|c|}
\hline First author [ref.] & Daily dose of randomised treatment & Concomitant LABA therapy & ICS-exposed patient & Cause of death \\
\hline Pauwels [26] & Formoterol $4.5 \mu \mathrm{g}$ p.r.n. & Salmeterol & Yes & Asthma \\
\hline Pauwels [26] & Formoterol $4.5 \mu \mathrm{g}$ p.r.n. & & No & Asthma \\
\hline O'Byrne [28] & $\begin{array}{c}\text { Formoterol/budesonide } 9 / 160 \mu \mathrm{g} \text { plus } \\
\text { terbutaline } 400 \mu \mathrm{g} \text { p.r.n. }\end{array}$ & & Yes & Asthma \\
\hline von BERG [33] & Formoterol $18 \mu \mathrm{g}$ & & Yes & Respiratory failure \\
\hline Pauwels [26] & Salbutamol $200 \mu$ g p.r.n. & & No & Asthma \\
\hline Pauwels [26] & Salbutamol $200 \mu$ g p.r.n. & & Yes & Asthma \\
\hline
\end{tabular}

LABA: long-acting $\beta$-agonist; ICS: inhaled corticosteroids. 
TABLE 2 Other causes of death

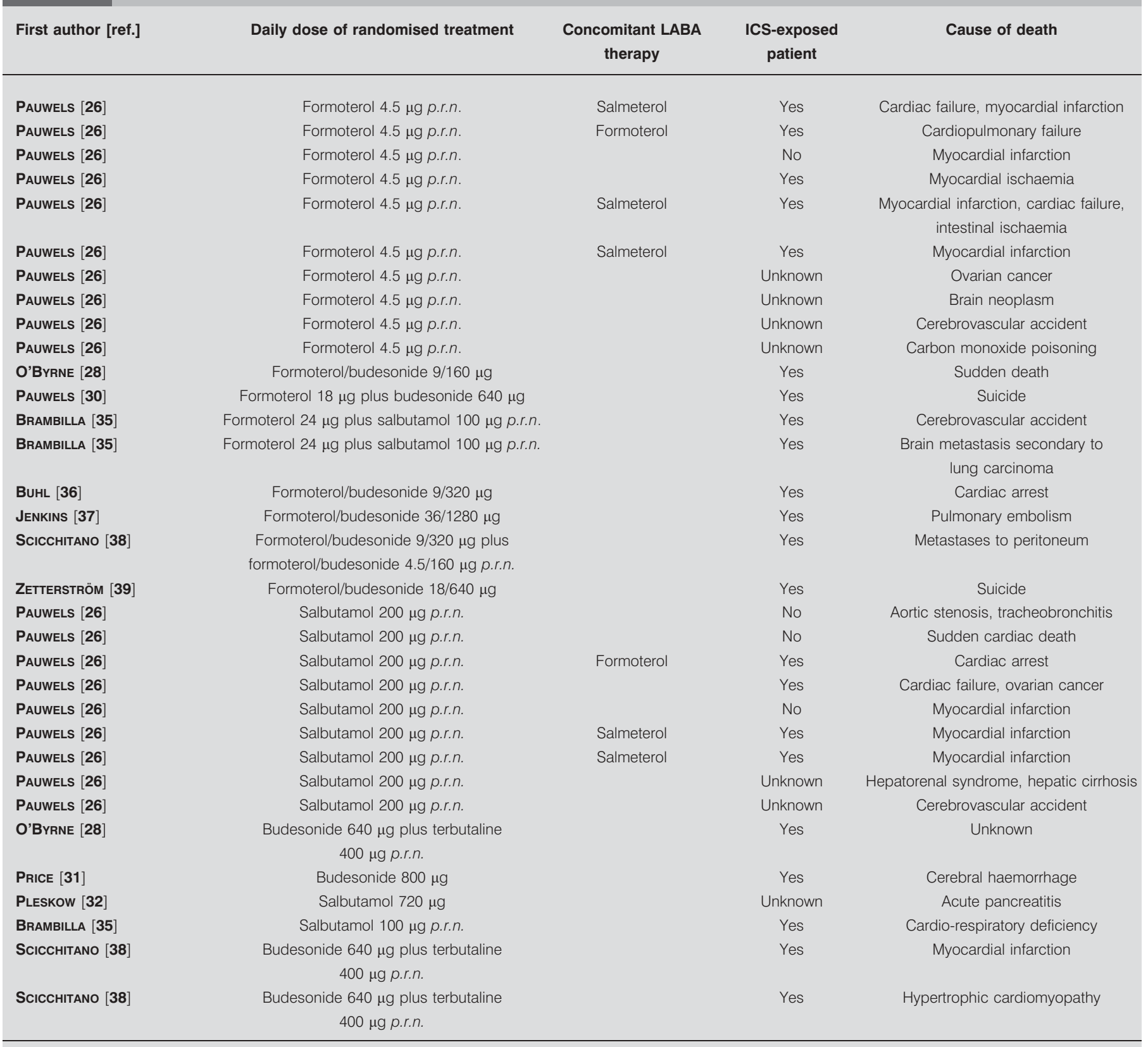

LABA: long-acting $\beta$-agonist; ICS: inhaled corticosteroids.

of the studies, including the number of subjects in each treatment group, the number and causes of death and other features, such as the age of subjects enrolled. We used the AstraZeneca database and the Novartis FDA submission as the preferred source of data, followed by published manuscripts and then abstracts.

Another issue was whether all deaths were identified from these studies. This was potentially problematic as, although we had expected that all studies in which deaths occurred would have reported these deaths in the published manuscript, this was not the case. In four large clinical trials, deaths which were reported in the AstraZeneca database were not mentioned in the published manuscript [28-31]. In response to this observation, we contacted all principal investigators of studies in which no information on deaths was reported, seeking this specific data. This enabled confirmation of the number of deaths and their treatment allocation from 54 out of the 62 studies included in the meta-analysis. Incidentally, the observed unreliability of mortality data in published clinical trials has implications beyond the current study.

A related issue is the difficulty in determining the exact cause of death, which is inherent in any clinical trial. It was for this reason that all-cause mortality was chosen as the primary outcome variable, although the main interest was whether 


\begin{tabular}{|c|c|c|c|}
\hline \multirow[t]{2}{*}{ TABLE 3} & \multicolumn{3}{|c|}{$\begin{array}{l}\text { Odds ratios for risk of death associated with } \\
\text { formoterol treatment at randomisation }\end{array}$} \\
\hline & & All deaths & Asthma deaths \\
\hline \multicolumn{4}{|c|}{$\begin{array}{l}\text { Simple contingency two-by-two } \\
\text { table method }\end{array}$} \\
\hline Formoterol & eaths ${ }^{\#}$ & 25/27821 (0.09) & $7 / 27821(0.03)$ \\
\hline Comparato & deaths ${ }^{\#}$ & $17 / 21506(0.08)$ & $2 / 21506(0.01)$ \\
\hline OR $(95 \%$ C & & $1.1(0.6-2.2)$ & $2.7(0.5-26.7)$ \\
\hline \multicolumn{4}{|c|}{ Peto's method } \\
\hline \multicolumn{4}{|c|}{ OR $(95 \% \mathrm{Cl})$} \\
\hline Fixed eff & & $1.2(0.6-2.2)$ & $2.8(0.7-10.4)$ \\
\hline Random & ffects & $1.2(0.6-2.2)$ & $2.8(0.7-10.4)$ \\
\hline \multicolumn{4}{|c|}{ Bayesian method } \\
\hline \multicolumn{4}{|c|}{ Relative risk (95\% credible interval) } \\
\hline Vague pr & & $1.1(0.5-2.5)$ & $2.0(0.4-10.1)$ \\
\hline Informati & e prior & $1.3(0.8-1.9)$ & $3.2(1.3-8.7)$ \\
\hline
\end{tabular}

formoterol increased the risk of death from asthma. We primarily sourced this data from the AstraZeneca database and the Novartis FDA submission, which in a few cases resulted in a different classification of the cause of death being used.

For inclusion in the meta-analysis, studies had to be randomised controlled trials of formoterol with a non-LABA comparator treatment. This contrasted with the approach of the recent formoterol meta-analysis, in which clinical trials without a non-formoterol comparator treatment were included [21], which led to an underestimate of the risk of mortality associated with formoterol treatment, as outlined in its accompanying editorial [22].

\section{Analytical issues}

Meta-analysis of trials with rare outcome measures is problematic and three methods of statistical analyses were undertaken. All three methods gave similar estimates of the relative death rate for formoterol compared with other treatments. The primary method was a single two-by-two table of events, which treats all trials as one large trial. This may be realistic if the trials have similar clinical samples and designs, but ignores the heterogeneity of the trials and may result in inappropriately narrow confidence intervals. The second method was calculation of the Peto's one-step odds ratio. A recent comprehensive analysis of the frequentist approach to metaanalysis of trials with rare events concluded that, under certain conditions, this method had the best performance [24]. These conditions, which include event rates $<1 \%$, no substantial imbalance between control and treatment group sizes within trials, and treatment effects that were not particularly large, were all met for the trials of formoterol included in the metaanalysis. The Peto method could only use information from 12 of the 62 trials, because there has to be at least one death in one arm of the trial to calculate a relative risk with this method.

\begin{tabular}{|c|c|c|c|}
\hline \multirow[t]{2}{*}{ TABLE 4} & \multicolumn{3}{|c|}{$\begin{array}{l}\text { Sensitivity analyses based on exposure to } \\
\text { formoterol, and exclusion of subjects taking } \\
\text { maintenance salmeterol treatment }\end{array}$} \\
\hline & & All deaths & Asthma deaths \\
\hline \multicolumn{4}{|c|}{$\begin{array}{l}\text { Simple contingency two-by-two } \\
\text { table method }\end{array}$} \\
\hline Formoterol & eaths ${ }^{\#}$ & 24/27,363 (0.09) & 6/27,363 (0.02) \\
\hline Comparatc & deaths ${ }^{\#}$ & $12 / 19,045(0.06)$ & $2 / 19,045(0.01)$ \\
\hline OR $(95 \%$ & & $1.4(0.7-3.1)$ & $2.1(0.4-21.2)$ \\
\hline \multicolumn{4}{|c|}{ Peto's method } \\
\hline \multicolumn{4}{|c|}{ OR $(95 \% \mathrm{Cl})$} \\
\hline Fixed eff & & $1.4(0.7-2.7)$ & $2.2(0.5-8.8)$ \\
\hline Random & ffects & $1.4(0.7-2.7)$ & $2.2(0.5-8.8)$ \\
\hline \multicolumn{4}{|c|}{ Bayesian method } \\
\hline \multicolumn{4}{|c|}{ Relative risk (95\% credible interval) } \\
\hline Vague $p$ & & $1.2(0.6-2.9)$ & $1.8(0.3-12.3)$ \\
\hline Informat & prior & $1.3(0.9-1.9)$ & $3.1(1.2-8.8)$ \\
\hline \multicolumn{4}{|c|}{$\begin{array}{l}\text { \#: presented as deaths/total subjects (\%). } \because \text { : the prior used for total deaths was } \\
\text { the confidence interval for the odds ratio for all deaths of } 0.8-2.1 \text { from SMART } \\
\text { (Salmeterol Multicentre Asthma Research Trial); for asthma deaths the } \\
\text { confidence interval } 1.2-15.3 \text { was used. }\end{array}$} \\
\hline
\end{tabular}

Both the simple two-by-two table method and the Peto method ignore information on the length of the trial.

The third method utilised the Bayesian approach which had the advantage that it can use the information about trials with no event in either arm to contribute to an overall estimate of event rate and can also incorporate information about the different length of follow-up. The approach can also incorporate prior knowledge about the possible size of the effect. If the dataset is sparse, the new estimates of effect size are dominated by the prior knowledge, so that the new "posterior" estimates are not modified by the data likelihood [40]. For both outcome variables, an estimate of the relative risk of death (total deaths and deaths due to asthma), together with a confidence interval, were available from the SMART trial [10]. This study represented the "worst case" scenario, obtained from the largest randomised placebo-controlled trial of LABAs and asthma mortality, with the findings providing the main cause for concern regarding the safety of LABAs. The major limitation of this approach was the poor generalisability of the SMART study, in particular the use of salmeterol without concomitant ICS therapy in patients with unstable asthma and the lack of medical supervision throughout the study.

Analyses were also undertaken in which subjects were classified according to exposure to formoterol or comparator treatment, after exclusion of subjects who were taking regular maintenance salmeterol treatment. This ensured that there was no bias introduced by concomitant salmeterol therapy, and that subjects randomised to comparator treatment but receiving maintenance formoterol were considered as exposed to formoterol. This approach was necessary as the RELIEF study [26], which contributed over half of the deaths in the meta-analysis, 
included around $30 \%$ of subjects who were receiving regular maintenance LABA therapy throughout the study.

\section{Main findings}

The main finding from this study was that there was insufficient power to determine the risk of asthma death associated with formoterol treatment. From 62 studies including almost 50,000 subjects, there were only 42 deaths, of which nine were asthma deaths, illustrating the difficulty in analysing such a rare outcome from large clinical trials of asthma treatment, even using meta-analysis. From the death rates in this meta-analysis, we calculated that at least 200,000 (80\% power) and 270,000 (90\% power) subjects are needed in a single randomised controlled trial of formoterol to have sufficient power to determine a 1.5-fold increased risk of allcause mortality.

The point estimates of a 2.0- to 3.2-fold increased risk of asthma mortality with formoterol could be viewed from at least three perspectives. It could be argued that formoterol is not associated with an increased risk of asthma mortality, as the odds ratios were not statistically significant apart from the informative prior Bayesian estimates based on the SMART trial [10]. Alternatively, due to the rare occurrence of death, the findings could be interpreted as suggesting that the study had insufficient power to determine whether formoterol is associated with an increased risk of death from asthma. The third interpretation is that the findings add weight to the evidence that LABAs may increase the risk of mortality, as supported by the Bayesian analysis, in which the prior estimate of risk of asthma death with salmeterol was used, based on the SMART study. Although this risk can be considered to represent the integration of the formoterol findings with prior knowledge of the risk with LABAs, this interpretation is limited by the poor generalisability of the SMART study to current recommended clinical practice. For this reason, we favour the second interpretation, with the qualification that the findings are not reassuring and certainly do not provide evidence that the use of formoterol is not associated with a mortality risk.

In assessing the clinical relevance of the low baseline rate of asthma death in these clinical trials there are two important considerations. The first is that the baseline rate of asthma mortality may be higher in clinical populations compared with participants in randomised controlled trials. Secondly, even if the baseline risk is low, the widespread use of a therapy that results in even a small increase in risk could still lead to an important population risk of mortality. We propose that an acceptable range for mortality risk should be part of the study design and suggest an upper confidence limit of risk of 1.5 may be appropriate for asthma mortality.

The small number of deaths also meant that we were unable to examine whether the risk was modified by prescription regimes for formoterol, such as use of concomitant ICS as separate and/or combination therapy, according to fixed dose, adjustable maintenance, or maintenance and reliever therapeutic regimes. This issue is clinically relevant, as the "as required for relief of symptoms" use of formoterol as a separate or combination inhaler carries a potential risk of overuse in the situation of a severe attack of asthma. Conversely, the use of combination ICS/LABA therapy could reduce the risk, as it ensures that LABAs cannot be used as monotherapy and may improve compliance with ICS therapy.

\section{Comparison with previous formoterol meta-analysis}

It is informative to compare our findings with those of the recent meta-analysis of the risk of formoterol, based on the AstraZeneca database [21]. As outlined in its accompanying editorial [22], when the analysis was restricted to trials with a non-LABA comparison group, the crude estimate of risk derived from the study by SEARS et al. [21] was 2.5, similar to our point estimates of risk of between 2.0 and 3.2. As a result, the findings between the two meta-analyses are consistent, using overlapping databases and different methods of analysis.

The main secondary outcome variable in the previous formoterol meta-analysis was the risk of exposure to formoterol when given in combination with ICS therapy [21]. This analysis could be undertaken in their database, as it included individual patient data, with a rate ratio for asthma mortality with formoterol of 3.7 when the analysis was restricted to patients prescribed ICS in trials with a non-LABA comparison group [22]. These findings suggest that concomitant use of ICS therapy may not protect against the risk of mortality with formoterol. The possible reasons for this finding are likely to be complex, and may relate to both direct pharmacological effects of formoterol and patterns of behaviour with its use. Pharmacological effects may relate to its regular use reducing bronchodilator sensitivity to $\beta$-agonists $[41,42]$ and inducing tolerance to its bronchoprotective effects [42]. Patterns of behaviour potentially include the use of formoterol in a separate inhaler reducing compliance with ICS therapy, owing to the good symptomatic control achieved [43] and the "as required" use, resulting in delay in seeking medical help in the situation of a severe exacerbation.

Conversely, LABAs in the form of a combination LABA/ICS product may increase compliance with ICS $[44,45]$ and for this reason have the potential to reduce the risk, owing to the dosedependent reduction in asthma mortality associated with ICS therapy [46]. However, there was only one asthma death amongst 6,331 patients randomised to combination formoterol/budesonide (Symbicort) therapy in our meta-analysis and, as a result, it was not possible to assess the risk of asthma mortality with this therapeutic approach owing to inadequate power. At the population level, combination LABA/ICS products also have the potential to reduce the risk of asthma mortality, if the strong patient and doctor preference for this therapeutic approach led to a greater overall use of ICS therapy than would otherwise occur [22]. This issue cannot be addressed from the randomised controlled trials included in our meta-analysis as it relates to patterns of prescribing in routine clinical practice.

\section{Future research}

The risk of asthma mortality associated with the LABAs formoterol and salmeterol must be determined, as their use with ICS is recommended as the optimal treatment for moderate and severe asthma $[19,20]$. This will require a major commitment from the pharmaceutical industry, regulatory authorities, the medical profession and, indeed, patients, if the research that is required to resolve this important issue is to be undertaken. We consider that a large randomised controlled 
trial of formoterol or salmeterol may not be feasible as it would require $\geqslant 200,000$ subjects with asthma, although this number could be reduced if the study was restricted to subjects with severe asthma, such as those with a recent hospital admission, a population that is at significant increased risk of mortality $[47,48]$. Other difficulties with planning such a study are the widespread global use of LABAs in severe asthma, making recruitment difficult. If a randomised controlled trial were to be undertaken, the priority would be to examine the safety of combination LABA/ICS products, the most commonly used form of LABAs.

The alternative epidemiological approach is to employ casecontrol study methodology, which may be regarded as the preferred method to determine the risk of such a rare outcome as mortality [49]. Such case-control methodology has been well established in the investigation of the risk of mortality associated with short-acting $\beta$-agonist therapy. Through this approach, a markedly greater risk of death was observed with fenoterol compared with salbutamol treatment, which led to fenoterol being identified as the major cause of the epidemic of asthma deaths in New Zealand in the 1970s and 1980s [5, 7, 50].

The findings from the six case-control studies of LABA therapy and near-fatal and/or fatal attacks of asthma that have been undertaken to date are reassuring in that no statistically significant increased risk has been identified, after adjusting for confounding variables [12-16, 51]. However, most of these studies have low power and report upper confidence limits that would support an increased risk of asthma death and/or lifethreatening attacks [13-16]. Therefore, we suggest that further case-control studies are urgently required. These studies would need to determine not only whether the use of LABA therapy is associated with death from asthma, but also whether there is any differential risk between salmeterol and formoterol, or management approaches such as regular maintenance, adjustable dosing, or maintenance and relief therapeutic regimes, whether specific ethnic groups [10] or children [52] may represent particular groups at increased risk, and whether combination LABA/ICS products may reduce the risk.

\section{SUPPORT STATEMENT}

The study was funded by a grant of NZ\$25,000 from MedSafe, New Zealand Ministry of Health. M. Wijesinghe is a Wellington Hospitals and Health Foundation Research Fellow and K. Perrin is a Health Research Council of New Zealand Training Fellow.

\section{STATEMENT OF INTEREST}

A statement of interest for R. Beasley and the study itself can be found at www.erj.ersjournals.com/misc/statements.dtl

\section{REFERENCES}

1 Lowell FC, Curry JJ, Schiller IW. A clinical and experimental study of isoprel in spontaneous and induced asthma. N Engl J Med 1949; 240: 45-51.

2 Van Metre TE. Adverse effects of inhalation of excessive amounts of nebulised isoproterenol in status asthmaticus. J Allergy 1969; 43: 101-113.

3 Inman WHW, Adelstein AM. Rise and fall of asthma mortality in England and Wales in relation to use of pressurized aerosols. Lancet 1969; ii: 279-285.
4 Stolley PD. Why the United States was spared an epidemic of deaths due to asthma. Am Rev Respir Dis 1972; 105: 883-890.

5 Crane J, Pearce N, Flatt A, et al. Prescribed fenoterol and death from asthma in New Zealand, 1981-83: a case control study. Lancet 1989; 1: 917-922.

6 Spitzer WO, Suissa S, Ernst P, et al. The use of beta-agonists and the risk of death and near death from asthma. N Engl J Med 1992; 326: 501-506.

7 Martinez FD. Safety of long-acting beta-agonists - an urgent need to clear the air. N Engl J Med 2005; 353: 2637-2639.

8 Hasford J, Virchow JC. Excess mortality in patients with asthma on long-acting $\beta_{2}$-agonists. Eur Respir J 2006; 28: 900-902.

9 Castle W, Fuller R, Hall J, et al. Serevent Nationwide Surveillance Study: comparison of salmeterol with salbutamol in asthmatic patients who require regular bronchodilator treatment. $\mathrm{Br}$ Med J 1993; 306: 1034-1037.

10 Nelson HS, Weiss ST, Bleecker ER, et al. The Salmeterol Multicenter Asthma Research Trial: a comparison of usual pharmacotherapy for asthma or usual pharmacotherapy plus salmeterol. Chest 2006; 129: 15-26.

11 Salpeter SR, Buckley NS, Orniston TM, et al. Meta-analysis: effect of long-acting beta-agonists on severe asthma exacerbations and asthma-related deaths. Ann Intern Med 2006; 144: 904-912.

12 Anderson HR, Ayres JG, Sturdy PM, et al. Bronchodilator treatment and deaths from asthma: case-control study. BMJ 2005; 330: 117.

13 Lanes SF, Garcia Rodriguez LA, Hueta C. Respiratory medications and risk of asthma death. Thorax 2002; 57: 683-686.

14 Williams C, Crossland L, Finnerty J, et al. Case-control study of salmeterol and near-fatal attacks of asthma. Thorax 1998; 53: 7-13.

15 Lanes SF, Lanza LL, Wentworth III CE. Risk of emergency care, hospitalization, and ICU stays for acute asthma among recipients of salmeterol. Am J Respir Crit Care Med 1998; 158: 857-861.

16 Meier CR, Jick H. Drug use and pulmonary death rates in increasingly symptomatic asthma patients in the UK. Thorax 1997; 52: 612-617.

17 Food and Drug Administration. Pulmonary Allergy Drugs Advisory Committee on the safety of long-acting beta-agonist bronchodilators. Summary Minutes of meeting 13 June 2005. www.fda.gov/ohrms/ dockets/ac/05/minutes/2005-4148M1_Final.pdf Last updated: 2005. Last accessed: July 2008.

18 Bateman E, Nelson H, Bousquet J, et al. Meta-analysis: effects of adding salmeterol to inhaled corticosteroids on serious asthmarelated events. Ann Intern Med 2008; 149: 33-42.

19 Global Initiative for Asthma. Global Strategy for Asthma Management and Prevention 2006. Global Initiative for Asthma, 2006. Available from www.ginasthma.org

20 British Thoracic Society, Scottish Intercollegiate Guidelines Network. British Guideline on the Management of Asthma: a national clinical guideline. Edinburgh, Scottish Intercollegiate Guidelines Network, 2005. Available from www.enterpriseportal2.co.uk/filestore/bts/ asthmaupdatenov05.pdf

21 Sears MR, Ottosson A, Radner F, et al. Long-acting $\beta$-agonists: a review of formoterol safety data from asthma clinical trials. Eur Respir J 2009; 33: 21-32.

22 Beasley R, Martinez FD, Hackshaw A, et al. Safety of long-acting $\beta$-agonists: urgent need to clear the air remains. Eur Respir J 2009; 33: $3-5$.

23 Novartis Briefing Document. Foradil Aerolizer. Submitted to Pulmonary Allergy Drugs Advisory Committee on the safety of long-acting beta-agonist bronchodilators. Basel, Novartis International AG, 2005. Available from www.fda.gov/ohrms/ dockets/ac/05/briefing/2005-4148B1_02_01-Novartis-Foradil.pdf

24 Bradburn MJ, Deeks JJ, Berlin JA, et al. Much ado about nothing: a comparison of the performance of meta-analytical methods with rare events. Statist Med 2007; 26: 53-77. 
25 Gelman A, Carlin JB, Stern HS, et al. Bayesian Statistical Analysis. 2nd Edn. Boca Raton, Chapman and Hall/CRC, 2004.

26 Pauwels RA, Sears MR, Campbell M, et al. Formoterol as relief medication in asthma: a worldwide safety and effectiveness trial. Eur Respir J 2003; 22: 787-794.

27 Noonan M, Rosenwasser LJ, Martin P, et al. Efficacy and safety of budesonide and formoterol in one pressurised metered-dose inhaler in adults and adolescents with moderate to severe asthma: a randomised clinical trial. Drugs 2006; 66: 2235-2254.

28 O'Byrne PM, Bisgaard H, Godard PP, et al. Budesonide/ formoterol combination therapy as both maintenance and reliever medication in asthma. Am J Respir Crit Care Med 2005; 171: 129-136.

29 O'Byrne PM, Barnes PJ, Rodriguez-Roisin R, et al. Low dose inhaled budesonide and formoterol in mild persistent asthma: the OPTIMA randomized trial. Am J Respir Crit Care Med 2001; 164 1392-1397.

30 Pauwels RA, Löfdahl C-G, Postma DS, et al. Effect of inhaled formoterol and budesonide on exacerbations of asthma. $N$ Engl J Med 1997; 337: 1405-1411.

31 Price D, Dutchman D, Mawson A, et al. Early asthma control and maintenance with eformoterol following reduction of inhaled corticosteroid dose. Thorax 2002; 57: 791-798.

32 Pleskow W, LaForce CF, Yegen U, et al. Formoterol delivered via the dry powder aerolizer inhaler versus albuterol MDI and placebo in mild-to-moderate asthma: a randomized, double-blind, doubledummy trial. J Asthma 2003; 40: 505-514.

33 von Berg A, Papageorgiu Saxoni F, Wille S, et al. Efficacy and tolerability of formoterol Turbuhaler $\mathbb{E}$ in children. Int J Clin Pract 2003; 57: 852-856.

34 von Berg A. Efficacy and tolerability of formoterol Turbuhaler ${ }^{\circledR}$ in children. Int J Clin Prac 2004; 58: 728.

35 Brambilla C, Le Gros V, Bourdeix I. Formoterol $12 \mu \mathrm{g}$ BID administered via single-dose dry powder inhaler in adults with asthma suboptimally controlled with salmeterol or on-demand salbutamol: a multicenter, randomized, open-label parallel-group study. Clin Ther 2003; 25: 2022-2036.

36 Buhl R, Creemers JPHM, Vondra V, et al. Once-daily budesonide/ formoterol in a single inhaler in adults with moderate persistent asthma. Respir Med 2003; 97: 323-330.

37 Jenkins C, Kolarikova R, Kuna P, et al. Efficacy and safety of high-

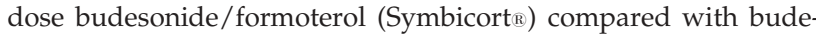
sonide administered either concomitantly with formoterol or alone in patients with persistent symptomatic asthma. Respirol 2006; 11 : 276-286.

38 Scicchitano R, Aalbers R, Ukena D, et al. Efficacy and safety of budesonide/formoterol single inhaler therapy versus a higher dose of budesonide in moderate to severe asthma. Curr Med Res Opin 2004; 20: 1403-1418.

39 Zetterström $\mathrm{O}$, Buhl $\mathrm{R}$, Mellem $\mathrm{H}$, et al. Improved asthma control with budesonide/formoterol in a single inhaler, compared with budesonide alone. Eur Respir J 2001; 18: 262-268.

40 Warn DE, Thompson SG, Spiegelhalter DJ. Bayesian random effects meta-analysis of trials with binary outcomes: methods for the absolute risk difference and relative risk scales. Statist Med 2002; 21: 1601-1623.

41 Newnham DM, McDevitt DG, Lipworth BJ. Bronchodilator subsensitivity after chronic dosing with eformoterol in patients with asthma. Am J Med 1994; 97: 29-37.

42 Yates DH, Sussman HS, Shaw MJ, et al. Regular formoterol treatment in mild asthma: effect on bronchial responsiveness during and after treatment. Am J Respir Crit Care Med 1995; 152: 1170-1174.

43 Arvidsson P, Larsson S, Löfdahl C-G, et al. Inhaled formoterol during one year in asthma: a comparison with salbutamol. Eur Respir J 1991; 4: 1168-1173.

44 Stempel DA, Stoloff SW, Carranza Rosenzweig JR, et al. Adherence to asthma controller medication regimens. Respir Med 2005; 99: 1263-1267.

45 Stoloff SW, Stempel DA, Meyer J, et al. Improved refill persistence with fluticasone propionate and salmeterol in a single inhaler compared with other controller therapies. J Allergy Clin Immunol 2004; 113: 245-251.

46 Suissa S, Ernst P, Benayoun S, et al. Low-dose inhaled corticosteroids and the prevention of death from asthma. N Engl J Med 2000; 343: 332-336.

47 Crane J, Pearce N, Burgess C, et al. Markers of risk of asthma death or readmission in the 12 months following a hospital admission for asthma. Int J Epidemiol 1992; 21: 737-744.

48 Rea HH, Scragg R, Jackson R, et al. A case-control study of deaths from asthma. Thorax 1986; 41: 833-839.

49 Pearce NE, Crane J. Epidemiological methods for studying the role of beta receptor agonist therapy in asthma mortality. In: Beasley R, Pearce NE, eds. The Role of Beta Agonist Therapy in Asthma Mortality. New York, CRC Press, 1993; pp. 68-83.

50 Pearce N, Beasley R, Crane J, et al., Epidemiology of asthma mortality. In: Holgate ST, Busse WW (eds). Asthma and Rhinitis. 2nd Edn. Oxford, Blackwell Scientific Press, 2000; pp. 58-69.

51 Wang M-T, Skrepnek GH, Armstrong E, et al. Use of salmeterol with and without concurrent use of inhaled corticosteroids and the risk of asthma-related hospitalization among patients with asthma. Curr Med Res Opinion 2008; 24: 859-857.

52 Bisgaard $\mathrm{H}$. Effect of long-acting $\beta_{2}$ agonists on exacerbation rates of asthma in children. Pediatr Pulmonol 2003; 36: 391-398. 